\title{
Gas Exchange Responses During Six Minute Walk Test In Patients With Pulmonary Arterial Hypertension
}

\author{
Norman. R. Morris ${ }^{1,2}$, H.Seale ${ }^{2}$, J.Harris ${ }^{2}$, K.Hall ${ }^{2}$, Aaron C. W. Lin ${ }^{1}$ and Fiona Kermeen ${ }^{2}$ \\ ${ }^{1}$ Menzies Health Institute, Queensland and Griffith University, Gold Coast, Australia \\ ${ }^{2}$ Queensland Lung Transplant Service, The Prince Charles Hospital, Brisbane, Australia
}

Abbreviated Title. Gas Exchange during 6MWT in PAH

\section{Contact Information.}

Norman R. Morris, PhD

Deputy Head of Research

School of Allied Health Sciences

Griffith University, Gold Coast, Australia

n.morris@griffith.edu.au 
Abstract

Introduction: The six-minute-walk test (6MWT) is the most widely utilized method of assessing exercise capacity in pulmonary arterial hypertension (PAH). Although has been shown to predict morbidity and mortality in PAH, the test is not without its limitations. Cardiopulmonary exercise test has the advantage of providing additional physiological information over 6MWT but it is technically more challenging to perform. The purpose of this study was to evaluate and compare the results from 6MWT, gas exchange and echocardiogram in three major subgroups of PAH. Methods: 76 PAH patients (idiopathic $n=28$, connective tissue disease $n=24$, congenital heart disease $\mathrm{n}=24$ ) completed 6MWT with simultaneous gas exchange measurements. Right ventricular systolic pressure (RVSP) was also obtained by echocardiography on the same day.

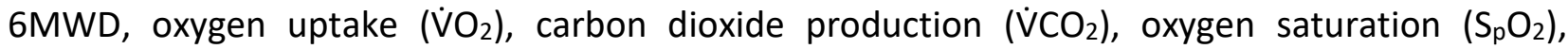
minute ventilation to carbon dioxide output $\left(\dot{\mathrm{V}}_{\mathrm{E}} / \dot{\mathrm{V}} \mathrm{CO}_{2}\right)$ and end-tidal partial pressure for carbon dioxide $\left(\mathrm{P}_{\mathrm{ET}} \mathrm{CO}_{2}\right)$ were compared between subgroups based on aetiology, functional class and pharmacotherapy. Results: Whilst no significant difference in $6 \mathrm{MWD}$ was observed, $\mathrm{V}_{2}$ and $\dot{\mathrm{VCO}}_{2}$ during $6 \mathrm{MWT}$ were lower in both the connective tissue disease and congenital heart disease subgroups. The congenital heart disease subgroup had the most significant desaturation during 6MWT than others (congenital: $73 \pm 15 \%$; Connective: $90 \pm 8 \%$, idiopathic: $92 \pm 8 \%$, $\mathrm{p}<0.01)$. Whilst there was no difference in $\dot{\mathrm{V}}_{\mathrm{E}} / \mathrm{V}_{\mathrm{CO}}$ and $\mathrm{P}_{\mathrm{ET}} \mathrm{CO}_{2}$ between different aetiology subgroups, we found that subjects in NYHA Functional Class (FC) II performed better in 6MWT and had lower $\dot{\mathrm{V}}_{\mathrm{E}} / \mathrm{VCO}_{2}$ and higher $\mathrm{P}_{\mathrm{ET}} \mathrm{CO}_{2}$ at end exercise than $\mathrm{FC}$ III subjects. Moreover, we found that a reduction in RVSP on follow-up echocardiogram was associated with an increase in 6MWD $(r=-0.55, p<0.05)$, a decrease in end-exercise $\dot{V}_{E} / \dot{V} C_{2}(r=0.66, p<0.01)$ and an increase in end-exercise $\mathrm{P}_{\mathrm{ET}} \mathrm{CO} 2$ ( $\left.r=-0.56, \mathrm{p}<0.05\right)$. Conclusion: Non-invasive gas exchange measurements may be useful additions to PAH progress and treatment monitoring than conventional 6MWD. Key Words. gas exchange, $\mathrm{P}_{\mathrm{ET}} \mathrm{CO} 2, \dot{\mathrm{V}}_{\mathrm{E}} / \dot{\mathrm{V}} \mathrm{CO}_{2}, 6 \mathrm{MWT}$, RVSP 
Introduction

Pulmonary arterial hypertension (PAH) is a rare but serious disease characterized by elevated mean pulmonary arterial pressure and pulmonary vascular resistance (PVR) [1]. Despite the diversity of aetiologies, patients with PAH typically present with exercise intolerance, progressive worsening in dyspnoea and, if left untreated, right ventricular failure and premature death[2]. While modern PAH-specific therapies can improve symptoms and possibly slow the rate of clinical deterioration in some PAH patients, most remain symptomatic with reduced exercise capacity, quality of life and survival despite optimized medical treatment [2].

Current guidelines recommend evaluation of exercise capacity in the assessment and follow up of $\mathrm{PAH}$ [3], with six minute walk test (6MWT) being the most widely utilized method of evaluation [3]. In countries such as Australia, 6MWT is a requirement for ongoing pharmaceutical benefits scheme allowance and is typically conducted at each clinic visit. This is because 6MWT is non-invasive, well-defined with standardized guidelines, simple to undertake [3], and the primary outcome, the six minute walk distance (6MWD), has been shown to predict morbidity and mortality in PAH $[4,5]$. While 6MWD has been accepted by regulatory authorities as an end-point for evaluating treatment effects in PAH, the test is not without its limitations [6, 7]. Specifically, 6MWT lacks sensitivity and specificity in the diagnosis of PAH, has a significant plateau effect, is not used in an age-adjusted fashion and provides no physiological details in the determinants of exercise limitation $[5,7,8]$. There is also evidence that a change in $6 \mathrm{MWD}$ is a poor surrogate end-point for clinical events [9]. As a result, recent studies evaluating treatment effects in PAH have moved away from using 6MWD as a primary end-point [7].

Current guidelines also recommend cardiopulmonary exercise testing (CPET) in evaluating exercise capacity in $\mathrm{PAH}$, with peak oxygen consumption $\left(\mathrm{V}_{2 \text { peak }}\right)$ being a recognized prognostic 
indicator for the disease $[7,10]$. Unlike 6MWT, CPET provides additional information on physiological limitations in PAH, particularly when other differential diagnoses are being considered [11]. Ventilatory inefficiency in PAH is a distinctive physiological abnormality characterized by an increase in minute ventilation to carbon dioxide output $\left(\dot{\mathrm{V}}_{\mathrm{E}} / \mathrm{V}_{\mathrm{CO}}\right)$ and a lower end-tidal partial pressure for carbon dioxide $\left(\mathrm{P}_{\mathrm{ET}} \mathrm{CO}_{2}\right)[12]$ which are observed both prior to and during exercise. Alteration in $\dot{\mathrm{V}}_{\mathrm{E}} / \mathrm{VCO}_{2}$ and $\mathrm{P}_{\mathrm{ET}} \mathrm{CO}_{2}$ during $\mathrm{CPET}$ have been shown to correlate with PAH disease severity and prognosis $[11,13,14]$. However, CPET is used far less commonly than 6MWT in the clinical setting, partly because in order to conduct a CPET, an ergometer, a metabolic cart to measure gas exchange and expertise in the administration and interpretation of the test are required [15]. Moreover, medical supervision is mandatory in this high risk population as recommended by the guidelines [15].

Recent studies have found that the addition of gas exchange measurements to an exercise test such as 6MWT may be feasible and that the exercise oxygen uptake $\left(\mathrm{V}_{2}\right)$ at completion of 6MWT correlated with that achieved during an incremental CPET $[16,17]$. Woods et al [18] reported that during a 3-minute submaximal exercise test, both $\dot{\mathrm{V}}_{\mathrm{E}} / \mathrm{VCO}_{2}$ and $\mathrm{P}_{\mathrm{ET}} \mathrm{CO}_{2}$ differentiated PAH patients from healthy controls and discriminated between different severities of $\mathrm{PAH}$.

The goals of our study were to describe the addition of gas exchange measurements to 6MWT and to determine how these parameters were related to severity of PAH.

\section{Methods}

\section{Patient population}

76 consecutive adult Group 1 PAH patients attending a tertiary pulmonary hypertension referral centre were included in this study. Subjects were further categorized into three subtypes 
according to their diagnosis: Idiopathic (IPAH, $n=28)$, connective tissue disease-related (CTPAH, $n=24)$ and congenital heart disease-related PAH (CHPAH, n=24). In addition, each subject was given a functional classification (NYHA FCI, II, III or IV) at the time of 6MWT by their attending physician. The study was approved by The Human Research Ethics Committee (HREC/14/QPCH/47) and all subjects gave written informed consent prior to commencement.

\section{Six Minute Walk Test}

The 6MWT was conducted using a standardized protocol [19]. Each subject completed 6MWT whilst wearing a portable metabolic system (Metamax, Cortex BXB, Lepzig, Germany). At each minute of 6MWT, severity of dyspnoea was determined using a 0-10 Scale of breathlessness.

\section{Ventilatory expired gas analysis}

During 6MWT test, each subject breathed through a mask (Hans Rudolph, Kansas City, USA) for the collection and analysis of expired gases. The metabolic system was calibrated for volume and expired concentrations of oxygen and carbon dioxide prior to each test. Minute-by-minute measurements of $\dot{\mathrm{VO}}_{2}$, carbon dioxide production $\left(\dot{\mathrm{V}} \mathrm{CO}_{2}\right)$, minute ventilation $\left(\dot{\mathrm{V}}_{\mathrm{E}}\right), \dot{\mathrm{V}}_{\mathrm{E}} / \dot{\mathrm{V} C \mathrm{C}_{2}}$, $\mathrm{P}_{\mathrm{ET}} \mathrm{CO}_{2}$ and oxygen saturation $\left(\mathrm{S}_{\mathrm{p}} \mathrm{O}_{2}\right)$ were recorded. Oxygen pulse $\left(\dot{\mathrm{VO}}_{2} /\right.$ heart rate) was also calculated.

\section{Echocardiographic evaluation}

As part of standard clinical protocol, all subjects completed echocardiographic evaluation of cardiac function on the same day as their 6MWT. Echocardiographic images were acquired using a $4 \mathrm{MHz}$ matrix array cardiac transducer (Vivid 7, General Electric, Milwaukee, WI, USA) with each subject in a semi-recumbent position. Right ventricular systolic pressure (RVSP) was determined from the tricuspid regurgitation (TR) velocity as per standard guidelines [20]. RV systolic function was examined by assessing the tricuspid annular plane systolic excursion (TAPSE). 
Statistical Analysis:

All statistical comparisons were performed using the SPSS statistical software package (Version 12.0, Chicago, IL). 6MWT and gas exchange responses were compared between PAH subgroups based on aetiology, NYHA FC and pharmacotherapy using parametric/non parametric one-way analysis or $t$-tests as required. Where required, a Chi Square test $\left(\chi^{2}\right)$ was used to compare differences in categorical groups. A Fischer Exact Test was used where the requirements for using a $\chi^{2}$ could not be met. With multiple comparisons, where significant differences were found, contrasts (Bonferroni and Dunets for parametric and non-parametric data, respectively) were used to determine the source of group differences.

\section{Results}

Baseline characteristics of the subjects are shown in Table 1. Subjects in the IPAH and CHPAH subgroups were younger than those in the CTPAH subgroup. Subjects were either NYHA FC II or III, with a similar proportion of each functional classification in the three aetiology subgroups. Mean RVSP was elevated but mean TAPSE was normal for the whole cohort. However, there was no significant difference in either mean RVSP or mean TAPSE between the aetiology subgroups.

The 6MWD and the end-exercise gas exchange data for each of the three aetiology subgroups are presented in Table 2 and the mean change in $\dot{\mathrm{VO}}_{2}, \dot{\mathrm{V}} \mathrm{CO}_{2}, \mathrm{SpO}_{2}$ and heart rate during 6MWT are shown in Figure 1. While no significant difference was observed in 6MWD or heart rate between the subgroups, $\mathrm{CTPAH}$ and $\mathrm{CHPAH}$ subjects had a lower mean $\dot{\mathrm{V}}_{2}$ and $\dot{\mathrm{V}}_{2}$ during and at end 6MWT when compared to IPAH subjects. However, there was no significant difference in $\dot{\mathrm{VO}}_{2}\left(\mathrm{I} \cdot \mathrm{min}^{-1}\right)$ and $\dot{\mathrm{V}} \mathrm{CO}_{2}$ between the CTPAH and CHPAH subgroups. CHPAH subjects also had significantly lower mean end-exercise $\dot{\mathrm{V}}_{\mathrm{E}}$ and $\mathrm{O}_{2}$ pulse compared to IPAH subjects, and desaturated to a greater extent during 6MWT with a much lower end-exercise $\mathrm{SpO}_{2}$ compared to 
both IPAH and CTPAH subjects. There was no significant difference in end exercise $\dot{\mathrm{V}}_{\mathrm{E}} / \mathrm{V}_{\mathrm{CO}}$ and $\mathrm{P}_{\mathrm{ET}} \mathrm{CO}_{2}$ among groups. Moreover the change in $\dot{\mathrm{V}}_{\mathrm{E}} / \mathrm{V} C O_{2}$ and $\mathrm{P}_{\mathrm{ET}} \mathrm{CO}_{2}$ from pre to end exercise was not significantly different among groups.

Comparisons of 6MWD and gas exchange by NYHA functional classification are shown in Figure 2. Fifty two subjects were FC II and twenty four were FC III. Aetiology of PAH was not significantly different between FC II and III (Table 1). Compared to FC II, the FC III subjects had significantly lower 6MWD and end-exercise $\dot{\mathrm{VO}}_{2}$ expressed in absolute (FC-III: $0.76 \pm 0.33$ I. $\mathrm{min}^{-1}$; FC-II: $0.99 \pm 0.35$ I. $\mathrm{min}^{-1}, \mathrm{p}=0.008$ ) and relative to body mass (Figure $2, \mathrm{p}<0.01$ ). There was no significant difference in the end exercise $\dot{\mathrm{V}}_{\mathrm{E}}$ and $\dot{\mathrm{V}}_{\mathrm{CO}} \mathrm{FC}$ II and FC III subjects. FC II subjects did have a significantly higher mean end exercise $\mathrm{P}_{\mathrm{ETCO}}$ (Figure 2, $\mathrm{p}<0.01$ ) and oxygen pulse ( $\mathrm{FC} \mathrm{II}$ : $7.4 \pm 2.2$ ml.beat $^{-1}$; FC III: $5.9 \pm 2.2$ ml.beat $^{-1}, \mathrm{p}<0.01$ ) and a lower mean end-exercise $\dot{\mathrm{V}}_{\mathrm{E}} / \mathrm{VCO}_{2}$ (Figure 2, $\mathrm{p}<0.01$ ) when compared to FC III subjects.

Comparison of changes in $\dot{\mathrm{V}}_{\mathrm{E}} / \mathrm{V}_{\mathrm{CO}}$ and $\mathrm{P}_{\mathrm{ET}} \mathrm{CO}_{2}$ during $6 \mathrm{MWT}$ for patients on monotherapy $(\mathrm{n}=35)$ and triple therapy $(n=18)$ are shown in Figure 3. There was no significant difference in 6MWD was found between mono- and triple therapy patients (502 $\pm 111 \mathrm{~m}$ vs $499 \pm 96 \mathrm{~m}, \mathrm{p}=0.92$ ). Both monotherapy and triple therapy groups had similar $\dot{\mathrm{V}}_{\mathrm{E}} / \dot{\mathrm{V}} \mathrm{CO}_{2}$ and $\mathrm{P}_{\mathrm{ET}} \mathrm{CO}_{2}$ pre exercise, however while no change was observed in $\dot{\mathrm{V}}_{\mathrm{E}} / \mathrm{VCO}_{2}$ and $\mathrm{P}_{\mathrm{ET}} \mathrm{CO}_{2}$ in the mono therapy group from pre to end-exercise, patients on triple therapy demonstrated a significant increase in mean $\dot{\mathrm{V}}_{\mathrm{E}} / \dot{\mathrm{V} C O} \mathrm{CO}_{2}$ and a decrease in mean $\mathrm{P}_{\mathrm{ET}} \mathrm{CO}_{2}$. Comparison of the therapy groups found there were proportionally fewer CHPAH and more IPAH subjects for the triple (IPAH, 10; CTPAH: 7; CHPAH: 3) compared to the monotherapy group (IPAH, 5; CTPAH: 8; CHPAH: 15) group $\left(\chi^{2}=8.6, d f=2\right.$, $p=0.013)$. The triple therapy group was slightly younger than the monotherapy group (monotherapy: $41 \pm 13 \mathrm{yr}$; triple: $51 \pm 15 \mathrm{yr}, \mathrm{p}=0.02$ ). Apart from these there were no other significant differences between the therapy groups. 


\section{Discussion}

To our best knowledge, this study is the first to report concurrent 6MWT and gas exchange measurements on three major subgroups of Group I PAH patients attending a tertiary referral centre. Our findings demonstrated that although no differences in end-exercise $\dot{\mathrm{V}}_{\mathrm{E}} / \dot{\mathrm{V}}_{\mathrm{E}} \mathrm{CO}_{2}$ and $\mathrm{PETCO}_{2}$ were found between the three subgroups, CHPAH and CTPAH subjects had a significantly lower $\dot{\mathrm{VO}}_{2}$ and $\dot{\mathrm{V}} \mathrm{CO}_{2}$ during exercise compared to IPAH subjects. CHPAH subjects also had more significant desaturation during 6MWT with a much lower end-exercise $\mathrm{S}_{\mathrm{P}} \mathrm{O}_{2}$ compared to IPAH and CTPAH subjects. When considered as a whole group, subjects who had shorter 6MWD also had a higher $\dot{\mathrm{V}}_{\mathrm{E}} / \dot{\mathrm{V}} \mathrm{CO}_{2}$, lower $\mathrm{P}_{\mathrm{ET}} \mathrm{CO}_{2}$ and a higher NYHA functional class. In addition, subjects on triple therapy had significantly higher $\dot{\mathrm{V}}_{\mathrm{E}} / \mathrm{V}_{\mathrm{CO}}$ and lower $\mathrm{P}_{\mathrm{ET}} \mathrm{CO}_{2}$ when compared to those on monotherapy despite having similar 6MWD.

Combining gas exchange measurements with 6MWT requires specialist equipment and expertise and as such only a few studies to-date have reported exercise gas exchanges responses in PAH. Deboek et al [16] examined the physiological responses in $20 \mathrm{PAH}$ patients during 6MWT and found that the mean 6MWD and end-exercise $\dot{\mathrm{VO}}_{2}$ to be similar to those reported in our study (450 metres and $0.901 . \mathrm{min}^{-1}$, respectively). PAH patients in their study were of mixed aetiologies including idiopathic, connective tissue disease, congenital, portal hypertension and fenfluramine related pulmonary hypertension. However, no differentiation was made between these subsets of patients. More recently, Mainguy et al [21] compared physiological responses to 6MWT, incremental exercise test, incremental shuttle walk test and endurance shuttle walk test in 21 PAH patients consisting of idiopathic, connective tissue disease, congenital and heritable PAH. The authors reported a similar 6MWD as our current study (447 m) and a similar end-exercise $\dot{\mathrm{V}} \mathrm{O}_{2}$. However, no differentiation was made between the different aetiologies. 
The major difference in exercise capacity between each of the aetiology subgroups in our study was highlighted by their gas exchange measurements showing a significantly lower $\dot{\mathrm{V}}_{2}$ and $\dot{\mathrm{V}}_{2}$ in $\mathrm{CTPAH}$ and $\mathrm{CHPAH}$ subjects. While the 6MWD was not significantly different between the three aetiology subgroups in our study, there was a tendency for the CTPAH and CHPAH subjects to perform less well in 6MWT than IPAH subjects. These findings may suggest that the addition of gas exchange measurements to 6MWT could increase the sensitivity in differentiating between aetiology subgroups.

Our results did not find any significant difference in end-exercise $\dot{\mathrm{V}}_{\mathrm{E}} / \mathrm{VCO}_{2}$ or $\mathrm{P}_{\mathrm{ET}} \mathrm{CO}_{2}$ between the three aetiology subgroups nor any change from pre to end exercise. However, when categorized by their functional class, FC III subjects tended to have shorter 6MWD and higher end-exercise $\dot{\mathrm{V}}_{\mathrm{E}} / \mathrm{VCO}_{2}$ and lower $\mathrm{P}_{\mathrm{ET}} \mathrm{CO}_{2}$. Whilst it is well documented that subjects with higher functional class have shorter 6MWD [22], our study is the first to report that PAH patients with higher functional class have higher end-exercise $\dot{\mathrm{V}}_{\mathrm{E}} / \mathrm{V} \mathrm{CO}_{2}$ and lower $\mathrm{P}_{\mathrm{ET}} \mathrm{CO}_{2}$.

We also found that changes in gas exchange response were sensitive to disease severity based on pharmacotherapy. This is a novel finding. Current management guidelines recommend a progressive up-titration in pharmacotherapy as the disease progresses [23]. As a result, individuals on triple therapy, whilst possibly well compensated, have more advanced disease compare to those on monotherapy. Our results suggested that even though the 6MWD is comparable, individuals on triple therapy tended to increase $\dot{\mathrm{V}}_{\mathrm{E}} / \mathrm{VCO}_{2}$ and lower $\mathrm{P}_{\mathrm{ET}} \mathrm{CO}_{2}$ during 6MWT. This was consistent with the findings recently reported by Woods et al.[18] who reported worsening gas exchange in more severe $\mathrm{PAH}$ patients during 3 minutes of box-stepping exercise. We found that our triple therapy group tended to be younger and contain more CHPAH patients. It is not clear if how these factors would impact on worsening gas exchange. 
To date, the majority of studies examining the relationship between gas exchange and maximal CPET in PAH patients demonstrated a typical pattern of a reduced $\dot{\mathrm{VO}}_{2 \text { peak, }}$ peak work rate, anaerobic threshold $(\mathrm{AT})$ and $\mathrm{P}_{\mathrm{ET}} \mathrm{CO}_{2}$. In addition, an elevated $\dot{\mathrm{V}}_{\mathrm{E}} / \dot{\mathrm{V}} \mathrm{CO}_{2}$ slope and functional dead space $\left(V_{D} / V_{T}\right)$ ventilation during maximal CPET were previously demonstrated in PAH patients [24]. In their landmark study, Yashanoubi et al [25] proposed an inverse hyperbolic relationship between $\mathrm{P}_{\mathrm{ET}} \mathrm{CO}_{2}$ and $\dot{\mathrm{V}}_{\mathrm{E}} / \mathrm{V} \mathrm{CO}_{2}$ measured at $\mathrm{AT}$ which categorised disease likelihood for $\mathrm{PAH}$. Individuals with the highest $\dot{\mathrm{V}}_{\mathrm{E}} / \mathrm{V} \mathrm{CO}_{2}$ and lowest $\mathrm{P}_{\mathrm{ET}} \mathrm{CO}_{2}$ at $\mathrm{AT}$ were categorised as most likely to have PAH and with worse severity.

The hallmark of ventilatory dysfunction in PAH is elevated $\dot{\mathrm{V}}_{\mathrm{E}} / \mathrm{VCO}_{2}$. Accompanying this is a decreased $\mathrm{P}_{\mathrm{ET}} \mathrm{CO}_{2}$. The exact mechanism of the abnormal ventilatory response remains unclear, however several possible interacting mechanisms have been proposed. Firstly, the increased PVR results in RV dysfunction and a blunted cardiac output during exercise. This cardiac dysfunction is characterised by increased RV end-diastolic and end-systolic volumes during exercise which would eventually impact on left ventricular function. As a result, exercising skeletal muscles become underperfused and an early onset of lactic acidosis at low work rates ensues [24]. Consequently, buffering of $\mathrm{H}^{+}$ions results in an increase in non-metabolic $\mathrm{CO}_{2}$ production due to the disassociation of carbonic acid leading to an increase in $\dot{\mathrm{V}}_{\mathrm{E}} / \mathrm{V} \mathrm{CO}_{2}$. Indeed, there is recent evidence that this early production of metabolic by-products in the skeletal muscles plays an important part in an increase in $\dot{\mathrm{V}}_{\mathrm{E}} / \mathrm{V}_{\mathrm{CO}}$ in chronic heart failure patients [26]. In a classic study, Olson et al.[27] blocked the activity group III and IV afferent nerves supplying the ergo/metaboreceptors in heart failure patients during submaximal exercise and reported a significant reduction in $\dot{\mathrm{V}}_{\mathrm{E}} / \dot{\mathrm{V}} \mathrm{CO}_{2}$. They concluded that the increased activity from the ergo/metaboreceptors during exercise results in an increased afferent input to the respiratory control centre, leading to an increased drive to breathe. 
Secondly, it is possible that peripheral chemoreceptors may be stimulated during exercise in PAH due to an exercise-induced arterial hypoxaemia. In our study, patients tended to de-saturate during exercise (mean end exercise $\mathrm{S}_{\mathrm{p}} \mathrm{O}_{2}: 90 \%$ ) which could result in an increased activity of peripheral chemoreceptors located in the carotid bodies. The underlying mechanism for arterial hypoxaemia remains unclear, however $\mathrm{V}-\mathrm{Q}$ mismatch, a shortened red blood cell transit time through the restricted pulmonary vascular bed and a reduced diffusion capacity have been proposed [28]. It is worth noting that in $\mathrm{PAH}$, a blunted cardiac output from the right ventricle may result in an increase in the functional dead space ventilation $\left(V_{D} / V_{T}\right)$. This in turn could lead to underperfusion of well-ventilated lungs and the resultant V-Q mismatch [24].

The results of the current study suggested that the addition of gas exchange analysis to 6MWD better correlated with disease severity than 6MWD alone. Whilst gas exchange abnormalities could be measured during CPET, the use of a portable system during 6MWT would negate the requirement for medical supervision. Moreover, patients do not have to exercise on a fixed ergometer in 6MWT, such as a treadmill or a cycle ergometer, of which they are unfamiliar.

\section{Limitations}

We were unable to obtain right heart catheter data on all subjects at the time when their first 6MWT was conducted. Hence we relied on the RVSP as a surrogate marker of the pulmonary arterial pressures. Nonetheless, the echocardiograms were performed on our PAH patients by the same sonographer and reported by the same Cardiologist. Secondly, PAH is a disease of significant heterogeneity and we have only studied a limited cohort of Group I patients. It is possible that other groups of PAH patients may have different gas exchange responses to 6MWT whichis beyond the scope of the current study. 


\section{Conclusions}

Our study reported that gas exchange measurements including $\mathrm{V}_{\mathrm{E}} / \mathrm{VCO}_{2}$ and $\mathrm{PET}_{\mathrm{ET}} \mathrm{CO}_{2}$ can be performed during 6MWT. These measures were not only better related to indices of disease severity of PAH than 6MWD alone, they could also potentially permit differentiation between subgroups of PAH. Results of the current study could provide clinicians and researchers the opportunity to incorporate these relatively simple measures into clinical practice and add incremental value in the management of $\mathrm{PAH}$ patients.

\section{Acknowledgements}

This research was supported by Queensland Health Research Practitioner Grant. 


\section{References}

1. Hoeper, M.M., et al., Definitions and diagnosis of pulmonary hypertension. J Am Coll Cardiol, 2013. 62 (25 Suppl): p. D42-50.

2. Tonelli, A.R., et al., Causes and circumstances of death in pulmonary arterial hypertension. Am J Respir Crit Care Med, 2013. 188(3): p. 365-9.

3. Galie, N., et al., 2015 ESC/ERS Guidelines for the diagnosis and treatment of pulmonary hypertension: The Joint Task Force for the Diagnosis and Treatment of Pulmonary Hypertension of the European Society of Cardiology (ESC) and the European Respiratory Society (ERS): Endorsed by: Association for European Paediatric and Congenital Cardiology (AEPC), International Society for Heart and Lung Transplantation (ISHLT). Eur Respir J, 2015. 46(4): p. 903-75.

4. Fritz, J.S., et al., Baseline and follow-up 6-min walk distance and brain natriuretic peptide predict 2-year mortality in pulmonary arterial hypertension. Chest, 2013. 143(2): p. 315-23.

5. Miyamoto, S., et al., Clinical correlates and prognostic significance of six-minute walk test in patients with primary pulmonary hypertension. Comparison with cardiopulmonary exercise testing. Am J Respir Crit Care Med, 2000. 161(2 Pt 1): p. 487-92.

6. Morris, N.R., et al., Serious adverse events during a 6-min walk test in pulmonary hypertension. Eur Respir J, 2015. 45: p. 1179-82.

7. Hassoun, P.M., et al., Updating clinical endpoint definitions. Pulm Circ, 2013. 3(1): p. 206-16.

8. Rubin, L.J., Diagnosis and management of pulmonary arterial hypertension: ACCP evidence-based clinical practice guidelines. Chest, 2004. 126(1 Suppl): p. 7S-10S.

9. Gabler, N.B., et al., Validation of 6-minute walk distance as a surrogate end point in pulmonary arterial hypertension trials. Circulation, 2012. 126(3): p. 349-56.

10. Galie, N., et al., Guidelines for the diagnosis and treatment of pulmonary hypertension. Eur Respir J, 2009. 34(6): p. 1219-63.

11. Markowitz, D.H. and D.M. Systrom, Diagnosis of pulmonary vascular limit to exercise by cardiopulmonary exercise testing. J Heart Lung Transplant, 2004. 23(1): p. 88-95.

12. Sun, X.G., et al., Exercise pathophysiology in patients with primary pulmonary hypertension. Circulation, 2001. 104(4): p. 429-35.

13. Oudiz, R.J., et al., Usefulness of right-to-left shunting and poor exercise gas exchange for predicting prognosis in patients with pulmonary arterial hypertension. Am J Cardiol, 2010. 105(8): p. 1186-91.

14. Oudiz, R.J., et al., Effect of sildenafil on ventilatory efficiency and exercise tolerance in pulmonary hypertension. Eur J Heart Fail, 2007. 9(9): p. 917-21.

15. Whaley, M.H., et al., American College of Sports Medicine's Guide to Clinical Exercise Testing and Prescription. Vol. 9. 2013, Philadelphia Lippincott Williams \& Wilkins.

16. Deboeck, G., et al., Physiological response to the six-minute walk test in pulmonary arterial hypertension. Eur Respir J, 2005. 26(4): p. 667-72.

17. Tueller, C., et al., Six-minute walk test enhanced by mobile telemetric cardiopulmonary monitoring. Respiration, 2010. 80(5): p. 410-8.

18. Woods, P.R., et al., The usefulness of submaximal exercise gas exchange to define pulmonary arterial hypertension. J Heart Lung Transplant, 2011. 30(10): p. 1133-42.

19. ATS statement: guidelines for the six-minute walk test. Am J Respir Crit Care Med, 2002. 166(1): p. 111-7.

20. Rudski, L.G., et al., Guidelines for the echocardiographic assessment of the right heart in adults: a report from the American Society of Echocardiography endorsed by the European Association of Echocardiography, a registered branch of the European Society of Cardiology, and the Canadian Society of Echocardiography. J Am Soc Echocardiogr, 2010. 23(7): p. 685-713; quiz 786-8.

21. Mainguy, $\mathrm{V}$., et al., Alternatives to the six-minute walk test in pulmonary arterial hypertension. PLoS One, 2014. 9(8): p. e103626.

22. Humbert, M., et al., Survival in patients with idiopathic, familial, and anorexigen-associated pulmonary arterial hypertension in the modern management era. Circulation, 2010. 122(2): p. 156-63. 
23. Galie, N., et al., Updated treatment algorithm of pulmonary arterial hypertension. J Am Coll Cardiol, 2013. 62(25 Suppl): p. D60-72.

24. Paolillo, S., et al., Exercise testing in the clinical management of patients affected by pulmonary arterial hypertension. Eur J Prev Cardiol, 2012. 19(5): p. 960-71.

25. Yasunobu, Y., et al., End-tidal PCO2 abnormality and exercise limitation in patients with primary pulmonary hypertension. Chest, 2005. 127(5): p. 1637-46.

26. Olson, T.P., M.J. Joyner, and B.D. Johnson, Influence of locomotor muscle metaboreceptor stimulation on the ventilatory response to exercise in heart failure. Circ Heart Fail, 2010. 3(2): p. 212-9.

27. Olson, T.P., et al., Influence of Locomotor Muscle Afferent Inhibition on the Ventilatory Response to Exercise in Heart Failure. Exp Physiol, 2013.

28. Steenhuis, L.H., et al., Diffusion capacity and haemodynamics in primary and chronic thromboembolic pulmonary hypertension. Eur Respir J, 2000. 16(2): p. 276-81. 
Table 1: Subject Characteristics

\begin{tabular}{lcccc} 
& Total $(\mathrm{n}=76)$ & IPAH $(\mathrm{n}=28)$ & CTPAH $(\mathrm{n}=24)$ & CHPAH $(\mathrm{n}=24)$ \\
\hline \hline Age $(\mathrm{yr})$ & $47 \pm 15$ & $46 \pm 15^{\mathrm{b}}$ & $55 \pm 13$ & $41 \pm 14^{\mathrm{b}}$ \\
Female/male & $57 / 19$ & $17 / 11$ & $21 / 3$ & $19 / 5$ \\
NYHA Functional Class (II/III) & $52 / 24$ & $19 / 9$ & $16 / 8$ & $18 / 6$
\end{tabular}

\section{Echocardiography}

\begin{tabular}{|c|c|c|c|c|}
\hline $\mathrm{RVSP}(\mathrm{mm} \mathrm{Hg})$ & $76 \pm 31$ & $79 \pm 25$ & $69 \pm 31$ & $86 \pm 23$ \\
\hline TAPSE (mm) & $18 \pm 5$ & $20 \pm 4$ & $19 \pm 4$ & $16 \pm 4$ \\
\hline LVEF (\%) & $64 \pm 7$ & $64 \pm 6$ & $66 \pm 4$ & $61 \pm 10$ \\
\hline \multicolumn{5}{|l|}{ Therapy } \\
\hline Mono & 38 & 7 & 12 & 16 \\
\hline Dual & 29 & 12 & 6 & 5 \\
\hline Triple & 19 & 9 & 6 & 3 \\
\hline
\end{tabular}

FC-I/II: New York Health Association Functional class I/II; FC-III: NYHA Functional class I; FEV 1 : Forced expiratory volume in 1s, FVC: Forced vital capacity; DLco: Diffusion capacity for carbon monoxide; RVSP: right ventricular systolic pressure; TAPSE: Tricuspid annular plane systolic excursion; IPAH: idiopathic pulmonary arterial hypertension; CTPAH: connective tissue disease related pulmonary arterial hypertension; $\mathrm{CHPAH}$ : congenital heart disease related pulmonary arterial hypertension. ${ }^{a} \mathrm{P}<0.01$ vs IPAH group. ${ }^{\mathrm{b}} \mathrm{P}<0.01$ vs connective tissue group 
Table 2: Six Minute Walk Distance and End-Exercise Gas Exchange

$$
\text { Total }(n=76) \quad \text { IPAH }(n=28)
$$

CTPAH $(n=24)$

CHPAH $(n=24)$

Group Effect ( $p$ value)

\begin{tabular}{|c|c|c|c|c|c|}
\hline 6MWD (m) & $490 \pm 108$ & $529 \pm 89$ & $473 \pm 110$ & $470 \pm 117$ & 0.11 \\
\hline $\mathrm{VO}_{2}\left(\mathrm{I} \cdot \mathrm{min}^{-1}\right)$ & $0.90 \pm 0.36$ & $1.10 \pm 0.41^{b}$ & $0.87 \pm 0.30^{a}$ & $0.76 \pm 0.25^{a}$ & 0.00 \\
\hline $\mathrm{VO}_{2}\left(\mathrm{ml} \cdot \mathrm{kg}^{-1} \cdot \mathrm{min}^{-1}\right)$ & $13.4 \pm 4.3$ & $14.5 \pm 5.1$ & $13.2 \pm 3.7$ & $12.5 \pm 3.5$ & 0.22 \\
\hline $\mathrm{VCO}_{2}\left(\mathrm{I} \cdot \mathrm{min}^{-1}\right)$ & $1.03 \pm 0.36$ & $1.22 \pm 0.38$ & $1.00 \pm 0.32^{\mathrm{a}}$ & $0.85 \pm 0.27^{a}$ & 0.00 \\
\hline $\mathrm{S}_{\mathrm{p}} \mathrm{O}_{2}(\%)$ & $85 \pm 13$ & $92 \pm 8$ & $90 \pm 8$ & $73 \pm 15^{\mathrm{ab}}$ & 0.00 \\
\hline$V_{E}\left(I \cdot m^{-1}{ }^{-1}\right)$ & $46.1 \pm 16.8$ & $53.5 \pm 17.8$ & $44.0 \pm 15.5$ & $40.1 \pm 13.81^{a}$ & 0.01 \\
\hline HR (beats. $\min ^{-1}$ ) & $132 \pm 25$ & $139 \pm 23$ & $131 \pm 22$ & $125 \pm 27$ & 0.10 \\
\hline HR (\% predicted) & $76 \pm 14$ & $79 \pm 12$ & $78 \pm 12$ & $70 \pm 17$ & 0.06 \\
\hline Breathlessness (0-10) & $3.9 \pm 1.6$ & $3.4 \pm 1.4$ & $4.2 \pm 1.4$ & $3.3 \pm 1.7$ & 0.08 \\
\hline $\mathrm{V}_{\mathrm{E}} / \mathrm{VCO}_{2}$ & $42.9 \pm 9.8$ & $42.0 \pm 9.1$ & $42.0 \pm 11.7$ & $44.2 \pm 9.3$ & 0.68 \\
\hline $\mathrm{O}_{2}$ pulse (ml/beat) & $6.9 \pm 2.3$ & $8.0 \pm 2.7$ & $6.6 \pm 1.9$ & $6.1 \pm 1.7^{a}$ & 0.01 \\
\hline $\mathrm{P}_{\mathrm{ET}} \mathrm{CO}_{2}(\mathrm{mmHg})$ & $26.5 \pm 5.8$ & $27.2 \pm 5.8$ & $27.4 \pm 6.6$ & $25.2 \pm 4.9$ & 0.35 \\
\hline
\end{tabular}

Table 2: IPAH: idiopathic pulmonary arterial hypertension; CTPAH: connected tissue disease-related pulmonary arterial hypertension; CHPAH: congenital heart disease-related pulmonary arterial hypertension; 6MWD: six minute walk distance; $\mathrm{VO}_{2}$ : oxygen uptake; $\mathrm{VCO}_{2}$ : carbon dioxide production; $\mathrm{SPO}_{2}$ :oxygen saturation; $\mathrm{HR}$ : Heart Rate; $\mathrm{V}_{\mathrm{E}}$ : minute ventilation; $\mathrm{V}_{\mathrm{E}} / \mathrm{VCO}_{2}$ : minute ventilation to carbon dioxide output; $\mathrm{P}_{\mathrm{ET}} \mathrm{CO}_{2}$ : end tidal carbon dioxide; $\mathrm{P}_{\text {CAP: }}$ non-invasive estimate of pulmonary capacitance. ${ }^{\mathrm{a}} \mathrm{P}<0.01$ vs IPAH group; ${ }^{\mathrm{b} P}<0.01$ vs Connective group. 
Figure 1. Changes in Oxygen Uptake, Carbon Dioxide Production, Saturation and Heart Rate During Six Minute Walk Test by PAH aetiology
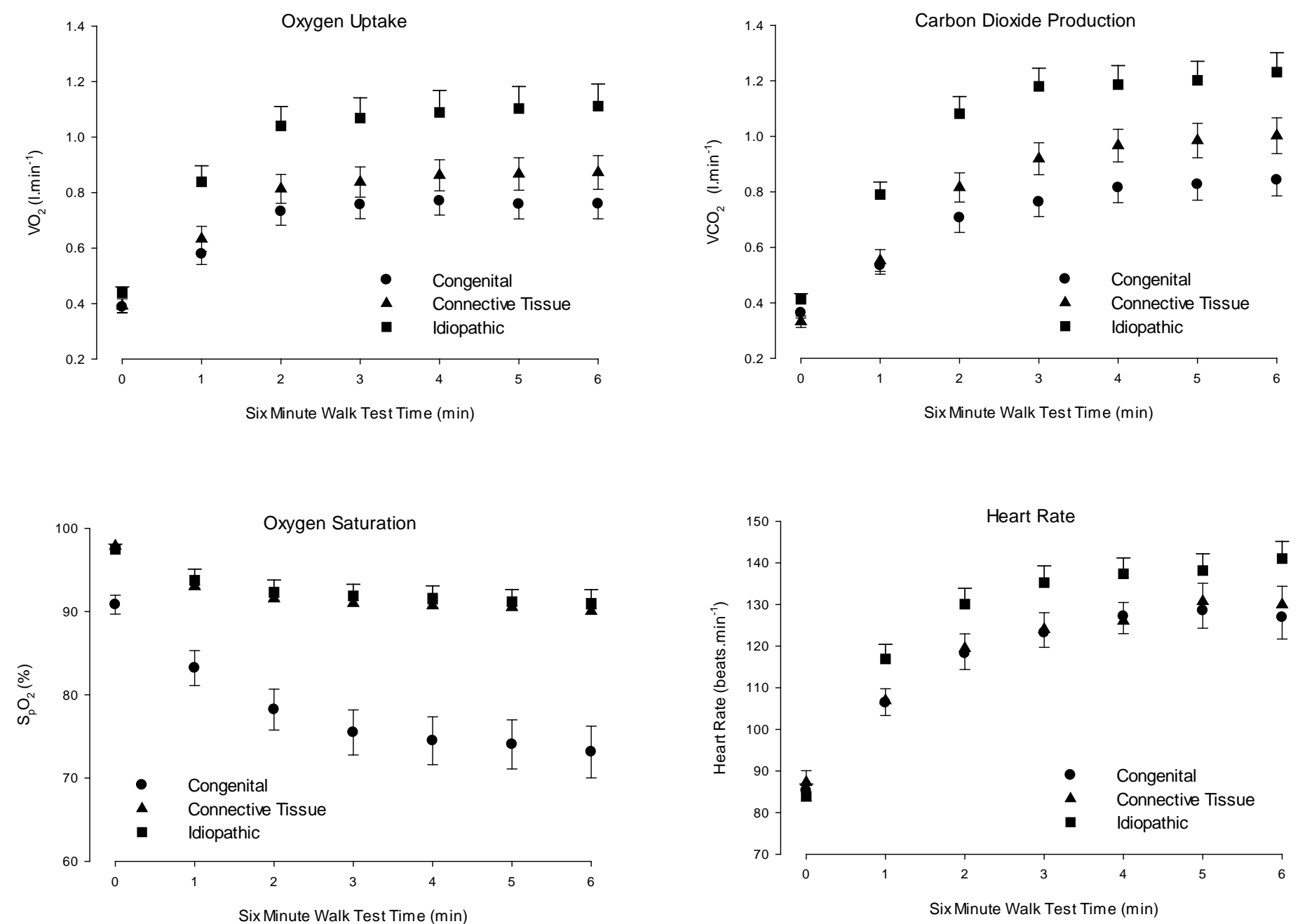
Figure 2. Six Minute Walk Distance and Gas Exchange Responses for Functional Class II vs III PAH Subjects
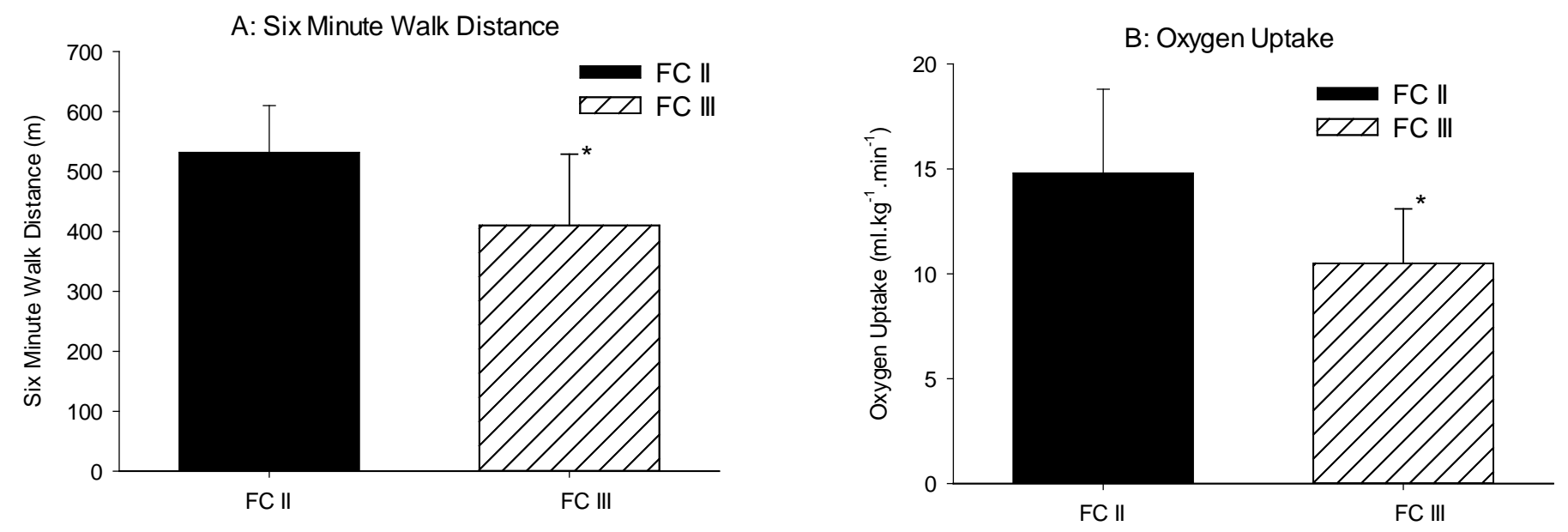

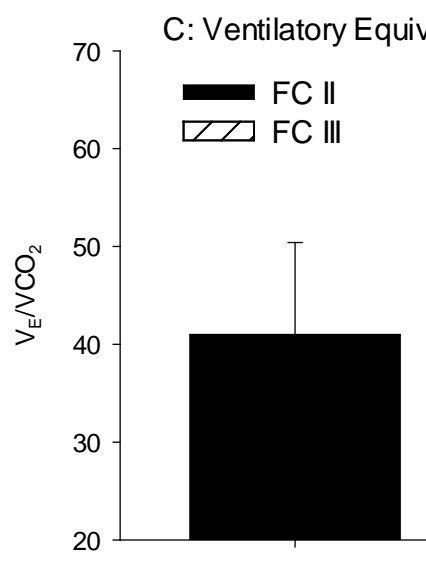

FC II
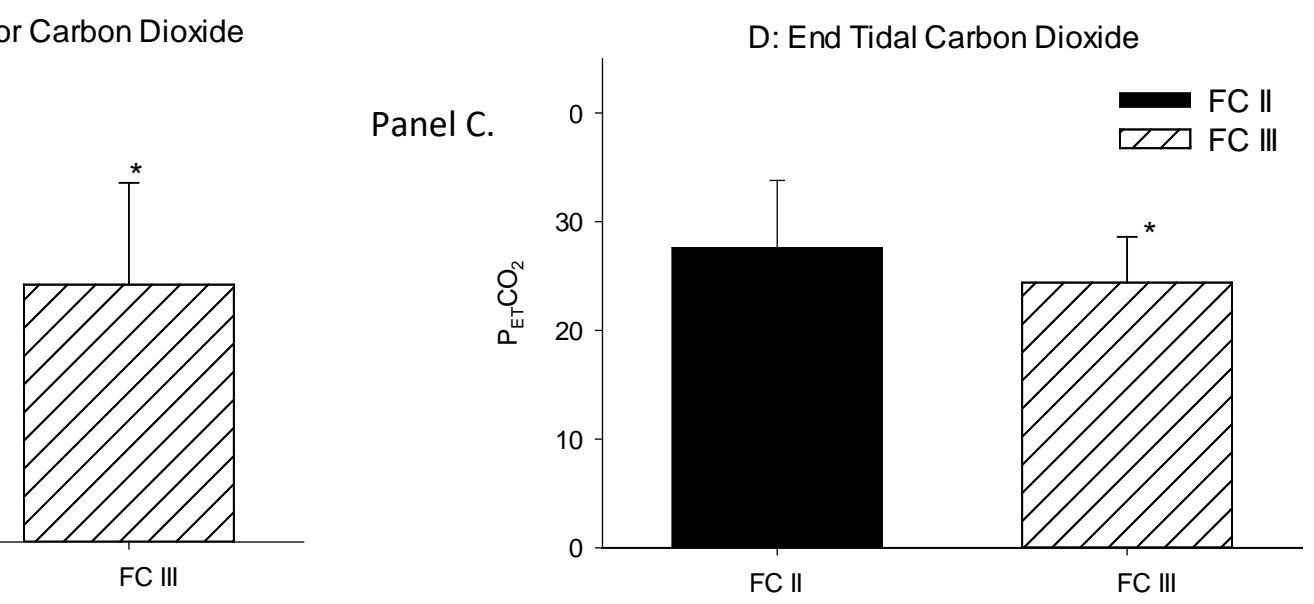

Panel A. 
Figure 3. Comparison of changes in ventilatoy efficiency during exercise between PAH subjects on monotherapy and triple therapy

Change in $\mathrm{V}_{\mathrm{E}} / \mathrm{NCO}_{2}$

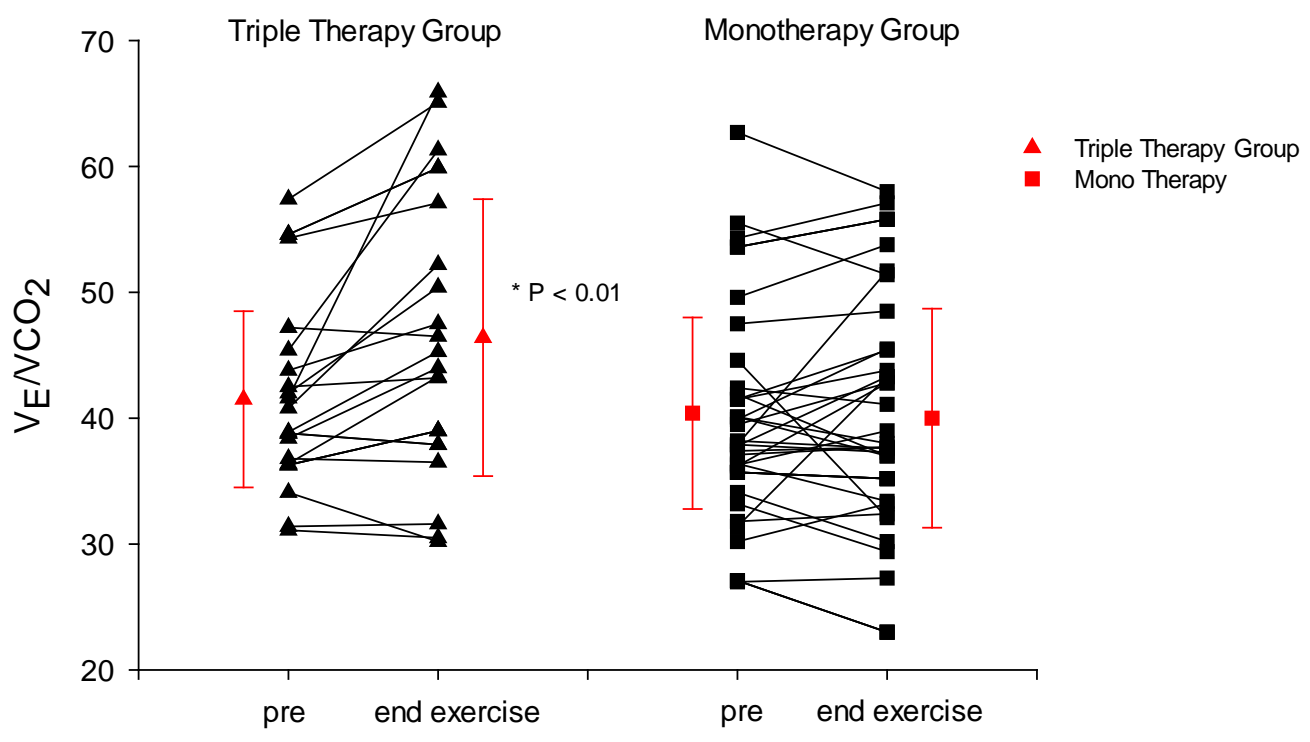

Change in $\mathrm{P}_{\mathrm{ET}} \mathrm{CO}_{2}$

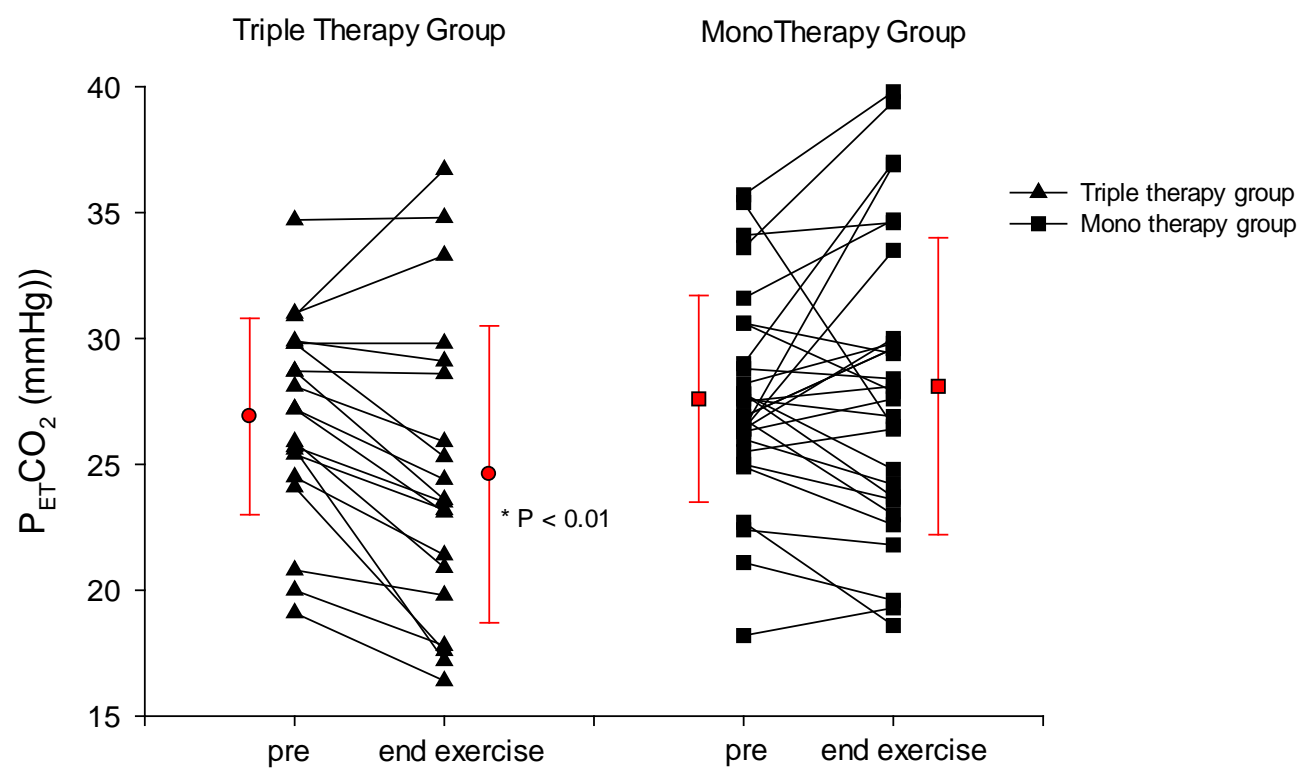


Figure 4. Change in Six Minute Walk Distance and Gas Exchange Variables Over Time
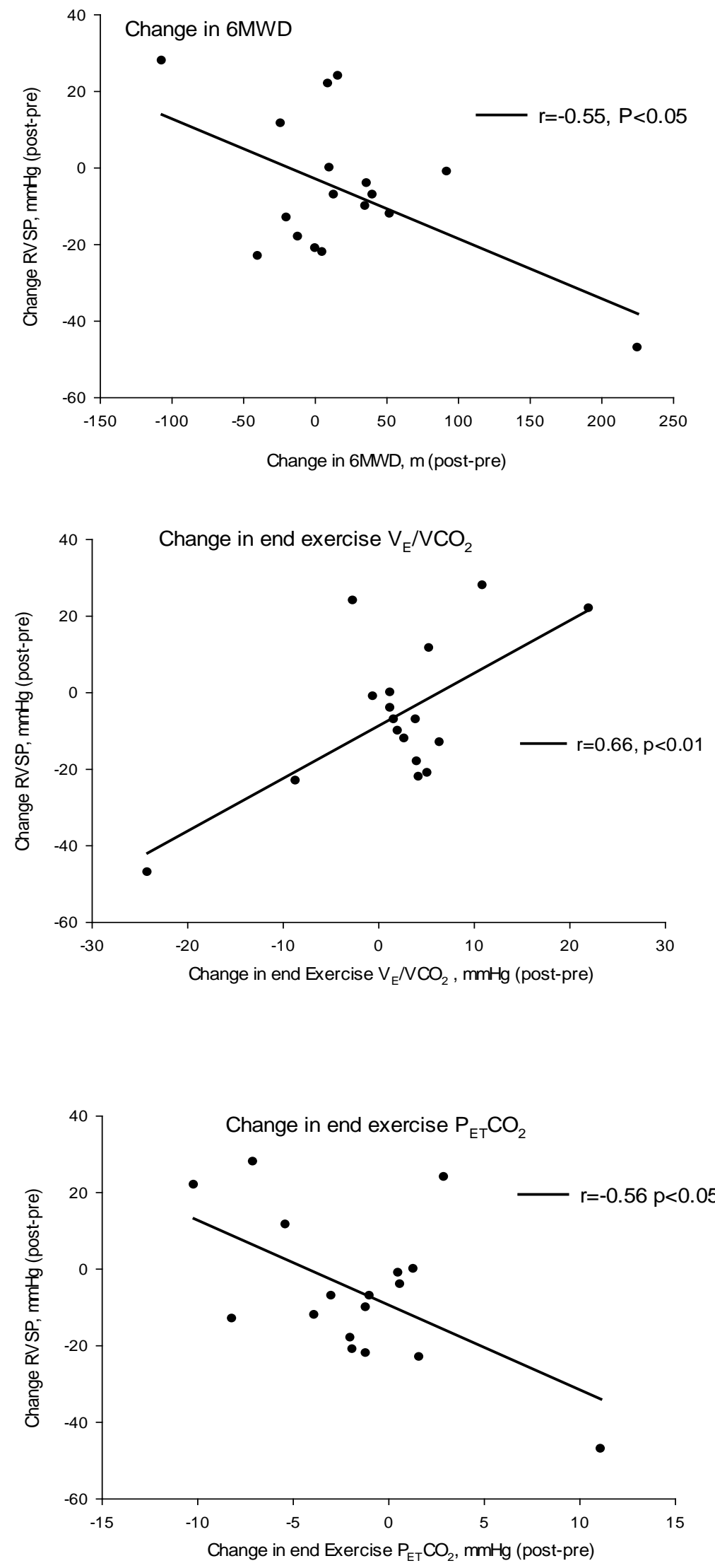
Figure Legends

Figure 1: Changes in Oxygen Uptake, Carbon Dioxide Production, Saturation and Heart Rate During Six Minute Walk Test. $\dot{\mathrm{V}} \mathrm{O}_{2}$ : Oxygen Uptake; $\mathrm{V}_{2}$ : Carbon Dioxide Production; $\mathrm{S}_{\mathrm{p}} \mathrm{O}_{2}$ : Oxygen Saturation. Data is mean \pm sem.

Figure 2: Six Minute Walk Distance and Gas Exchange Measures for Functional Class II vs III PAH Subjects. PAH: Pulmonary Artery Hypertension; FC: Functional Class; $\dot{\mathrm{V}}_{\mathrm{E}} / \dot{\mathrm{V}}_{\mathrm{CO}}$ : Ventilatory equivalent for carbon dioxide; $\mathrm{P}_{\mathrm{ET}} \mathrm{CO}_{2}$ : End tidal carbon dioxide. ${ }^{*} \mathrm{P}<0.05$ vs Functional Class II

Figure 3. Changes in $\dot{\mathrm{V}}_{\mathrm{E}} / \mathrm{V} \mathrm{CO}_{2}$ and End Tidal Carbon Dioxide for Monotherapy and Triple Therapy Groups.

Figure 4. Changes in Six Minute Walk Distance and Gas Exchange Variables Over Time. RVSP: Right Ventricular Systolic Pressure; 6MWD: Six Minute Walk Distance $\dot{\mathrm{V}}_{\mathrm{E}} / \mathrm{VCO}_{2}$ and: Ventilatory equivalent for carbon dioxide; $\mathrm{P}_{\mathrm{ET}} \mathrm{CO}_{2}$ : End tidal carbon dioxide. Pre: Initial clinic visit; Post: Most recent clinic visit. . A decrease in RVSP is represented by a negative number. 